\title{
SOME PHOTOGRAMMETRIC AND GEODETIC ASPECTS OF MEASUREMENT OF GLACIER SURFACE MOVEMENT AS FUNCTION OF TIME
}

\author{
By Ron K. H. Adler* \\ (Department of Geodetic Science, The Ohio State University, Columbus, Ohio, U.S.A.)
}

\begin{abstract}
The ice movement on the Byrd Glacier, Antarctica, was measured as function of time, on the basis of aerial photography. The method of aero-levelling strip triangulation with a minimum of geodetic control was applied. The methods and procedures were verified over Laufen-Bauma test area.

RÉsumé. Le mouvement de la surface du glacier Byrd, Antarctique a été mesuré en fonction du temps par photographie aérienne. La méthode d'aéronivellement par bande a été employée minimum de points avec le géodésiques de contrôle. Les méthodes et les procédés utilisés ont été vérifiés sur la région de contrôle de Laufen-Bauma en Suisse.

Zusammenfassung. Die Eisbewegung auf dem Byrd Gletscher in der Antarktis wurde mit Luftaufnahmen in ihrem zeitlichen Ablauf gemessen. Die Aeronivellement-Streifentriangulationsmethode wurde angewendet, wobei Minimum von gegebenen Passpunkten zur Verfügung stand. Die angewandten Methoden und Verfahren wurden auf dem Prüffeld Laufen-Bauma in der Schweiz geprüft.
\end{abstract}

\section{INTRODUCTION}

The problem of measurement of glacier surface movement as function of time can be solved by periodically repeated determination of position of a suitably chosen number of points on the glacier surface. If the positions are expressed within a certain particular coordinate system, the relative differences will permit the evaluation of magnitude and direction of the ice movement.

Such periodical determinations require the establishment of a system of control points situated outside the moving glacier surface to which all measurements and evaluations can be subsequently referred.

Glacier regions are generally situated in areas where the terrain and climatic conditions are not conducive to ground surveys. This is particularly true in the Antarctic. The instrumental work in the field connected with determination of position of a fairly large number of points, e.g. by the method of intersections, may take at least several days. During this time some displacement of the glacier surface will have occurred, which introduces a considerable complication of the problem. It is therefore essential that field work should be reduced to the minimum and this can be achieved by the application of photogrammetric methods.

Aerial triangulation is a method which provides a very satisfactory solution to the problem, adding additional advantages of an almost simultaneous recording of the situation over the whole glacier by means of air photography and permitting all measurements except those of control points, to be carried out at a chosen time under laboratory conditions.

\section{Photogrammetric Determination of Byrd Glacier Movement}

The problem of application of strip aerial triangulation to the measurement of glacier surface movement has been investigated by the author under the guidance of Dr. A. J. Brandenberger at the Ohio State University, whose research group has been active in glacier mapping for scientific purposes (Brandenberger i963).

* Present address: Head, Division of Topography, Survey of Israel, P.O.B. 2730, Tel Aviv, Israel. 
The glacier under investigation was the Byrd Glacier in the Antarctic (Swithinbank, 1963) (see Fig. I), the approximate width of which is $25 \mathrm{~km}$.

Two strips of vertical air photographs flown across the glacier were available, taken in November I960 and October 196 r respectively. A standard wide-angle camera of $154 \mathrm{~mm}$. focal length and $23 \mathrm{~cm}$. $\times 23 \mathrm{~cm}$. format with a sixty per cent longitudinal overlap was employed on each mission, the respective average flying heights being 5, $100 \mathrm{~m}$. and 6,300 $\mathrm{m}$. above the glacier.

The ground control available was extremely meagre, one reliable point being available at each end of the strip, situated outside the moving glacier surface, approximately $34 \mathrm{~km}$. apart on surrounding plateaus. Several additional elevation points were available on the glacier surface itself, but the reliability of their identification on air photos was very questionable.

A local plane rectangular system was established and oriented on the basis of the two ground control points and all subsequent evaluations were referred to it.

The aero-levelling method of strip triangulation was selected, which utilizes altimeter or statoscope readings taken during the flight for each individual photograph to compute the relative differences in elevation between the air stations, which are introduced as $b z$ values in the stereo instrument during triangulation by using the equation

$$
b z_{i}=100 \cdot 00 \mathrm{~mm} . \pm \Delta H_{i}{ }^{\prime} M_{M}
$$

where $100 \cdot 00 \mathrm{~mm}$. is the zero value of the $b z$ scale and $M_{M}$ the selected machine scale. The first strip contained II and the other I 2 models.

The Wild Autograph $\mathrm{A}_{7}$ was used for all aerial triangulations described in this work. Optical mechanical relative orientation procedure was followed throughout, with a slight modification to allow for the pre-computed $b z$ readings. Machine scale was $I: 20,000$. The absolute orientation of the first model was carried out using the available points (i.e. one ground control point and three aneroid elevations on the glacier surface) and the triangulations followed across the glacier, reading machine coordinates of points selected previously for measurement. These points were chosen in such a way that they formed three approximately parallel rows across the glacier and were identifiable on both strips. No difficulty was encountered in finding characteristic points such as ends of crevasses, sharp protrusions, etc.

The propagation of errors in aero-levelling can be expressed by the following equations:

$$
\begin{aligned}
& \Delta x=a_{o}+a_{1} x+a_{2} x^{2}, \\
& \Delta y=b_{o}+b_{1} x+b_{2} y^{2}, \\
& \Delta H=c_{o}+c_{1} x .
\end{aligned}
$$

Equation (2a) expresses primarily the effect on the $x$ values of the scale errors correlated with height errors, which results in a parabolic falsification of the $x$ machine coordinates. Actually a third-order term should be included in equation (2a) to allow for the bending of the strip in the $y$ direction caused by systematic error of swing. However, considering the accuracy limitations of aero-levelling this can be disregarded. Equation (2b) expresses primarily the parabolic falsification of $y$ machine coordinates caused by the systematic swing error. Equation (2c) expresses the linear propagation of height errors, which is peculiar to aero-levelling. Thus, three control points are required to determine the coefficients for each longitudinal section to obtain the $\Delta x$ and $\Delta y$ values and the third point should fall preferably in the middle of the strip.

In aerial triangulation across glacier surface which is not stable the provision of a control point in the middle of the strip is out of question. Due to this fact the strips were adjusted linearly on the basis of the two terminal control points at each end. 


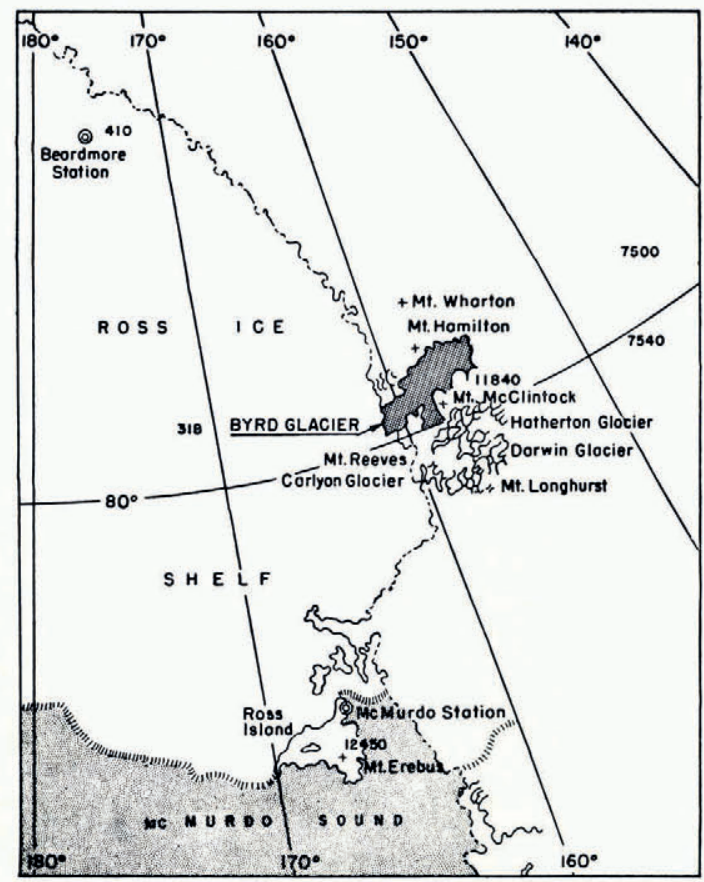

Fig. I. Location map

Using eight points outside the glacier as criterion and regarding their terrestrial coordinates obtained from the first strip as errorless, the following standard errors were obtained for the terrestrial coordinates computed from the second strip:

$$
m_{x}= \pm \mathrm{II} \cdot 2 \mathrm{~m} ., \quad m_{y}= \pm \mathrm{II} \cdot 9 \mathrm{~m} .
$$

Subsequently the horizontal components of the ice flow $\Delta X$ and $\Delta r$ were computed for each of the selected points on the surface of the Byrd Glacier:

$$
\Delta X=X_{1961}-X_{1960} \text { and } \Delta Y=Y_{1961}-Y_{1960}
$$

and their resultant (the flow distance)

$$
D=(\Delta X)^{2}+(\Delta Y)^{2}
$$

The azimuth of each flow line was computed from

$$
\tan X_{i}=\frac{\Delta Y_{i}}{\Delta X_{i}}
$$

The results presented graphically in Figure 2 show decisively the existence of the ice movement on the Byrd Glacier between November 1960 and October $196 \mathrm{I}$, which varies from approximately $50 \mathrm{~m}$. at the edges to the maximum of approximately $850 \mathrm{~m}$. at the center. Azimuths of the flow lines show the directional behavior of the movement. The horizontal displacement observed can also be expressed as rate of movement, based on the observing period of 348 days. Considering the middle part of the glacier, the average observed total movement was $803.3 \mathrm{~m}$. $\pm \mathrm{I}$ per cent. This expressed as a velocity gives $2.3 \mathrm{I} \mathrm{m}$./day over the observing period. 


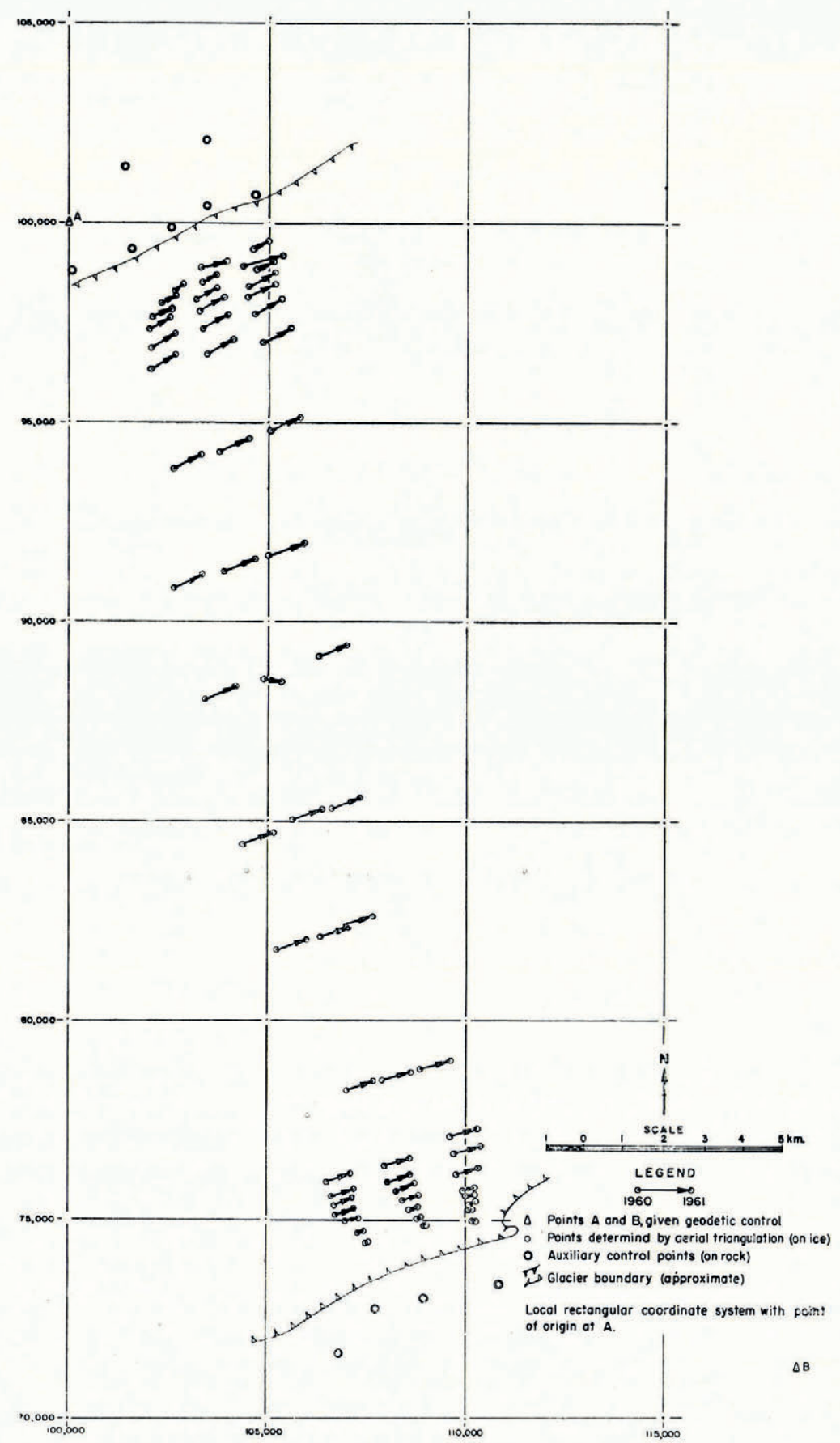

Fig. 2. Mab showing the flow vectors, Byrd Glacier, Antarctica, for the period 20 Norember 196o to 24 Octoher 1961 


\section{Verification of Methods and Procedures Employed}

The inadequate geodetic control available and the unorthodox procedures followed made the Byrd Glacier results rather uncertain as to their accuracy. In view of this the author verified the procedures and methods employed by simulating similar conditions over a test area. The test area chosen was the well known Laufen-Bauma area in Switzerland, which was used in several scientific investigations conducted by the Organisation Européenne pour des Études Photogrammétriques Experimentales and the International Society of Photogrammetry. The Laufen-Bauma area has a dense network of geodetic ground control, determined with cadastral accuracy of approximately $\pm 5 \mathrm{~cm}$.

The strip investigated was photographed with a Wild RG7 camera, focal length $100 \cdot 26 \mathrm{~mm}$. picture size $14 \mathrm{~cm}$. $\times$ I $4 \mathrm{~cm}$., flown at an average height of $6,000 \mathrm{~m}$. above the ground. A Wild Statoscope provided the data from which $b z$ elements were pre-computed.

Following the principle of aero-levelling and a linear adjustment of $X$ and $Y$ coordinates on the basis of 3 points at the beginning and 2 points at the end of the strip, the following standard errors were obtained for 30 control points spread uniformly throughout the strip:

$$
m_{X}= \pm \mathrm{I} \cdot 8 \mathrm{~m} ., \quad m_{Y}= \pm 2 \cdot 7 \mathrm{~m} .
$$

The elevation errors were left unadjusted and their standard error was $m_{H}= \pm 3 \cdot 2 \mathrm{~m}$.

\section{Conclusions}

The above results fully justify the procedures adopted for the Byrd Glacier triangulations. The standard errors obtained are very reasonable considering that linear and not parabolic adjustment was made. The smaller scale of photography used in the verification experiment was compensated by better quality of photography than in the original investigation.

In investigations similar to the one described here particular consideration should be given to the following points:

(I) The aerial photography should be flown at regular intervals of say one year, preferably on the same date each year and at the same time of day. The same flight line should be adhered to on each mission, the same good quality survey camera or one of very similar characteristics should be employed and the flights should be made at the same height above the glacier.

(2) Geodetic ground control can be reduced to the minimum as outlined above, that is, three points at the beginning of the strip and two at the end, located outside the glacier surface. If the control points are suitably signalized or prominently located they can be used for repeated evaluations.

(3) The points used for measurement within the aerial triangulation should be identifiable on the strips flown on different dates. If the type of glacier surface makes identification difficult the points would have to be pre-signalized.

(4) The aero-levelling procedure seems to be the best to combine with the principle of linear adjustment and geodetic control reduced to the minimum. One should realize that the main limiting factor of accuracy achievable is the precision of statoscope or altimeter used during the flight. However, the results obtained will permit the evaluation of magnitude and direction of the ice movement with accuracy sufficient for most glaciological investigations.

\section{Acknowledgements}

The Byrd Glacier investigation was made possible by grants from the National Science Foundation to the University of Michigan. The writer would like to thank Dr. C. W. M. 
Swithinbank, Head, Glacial Geology and Polar Research Laboratory, University of Michigan, who initiated the Byrd Glacier investigation. Dr. A. J. Brandenberger, of the Department of Geodetic Science, the Ohio State University, gave valuable advice and criticism in all stages of this work.

MS. received 12 Seplember 1963

\section{REFERENCES}

Brandenberger, A. J. 1963. Periodical photogrammetric mapping of glaciers in western United States for glaciological studies. Columbus, Ohio, Ohio State University Research Foundation.

Swithinbank, C. W. M. I963. Ice movement of valley glaciers flowing into the Ross Ice Shelf, Antarctica. Science, Vol. 141. No. $35^{80}$, p. 523-24. 